\title{
Enabling ICT adoption in developing Knowledge Societies
}

\author{
Colin Harrison \\ Director of Strategic Innovation, IBM Global Services EMEA Strategic Outsourcing, IBM \\ Zurich Research Laboratory, Säumerstrasse 4, 8803 Rüschlikon, Switzerland
}

ch@zurich.ibm.com; http://www.research.ibm.com/people/c/colinh

Abstract: The deployment of ICT in its present form requires simultaneously mastering of many skills and having a developed infrastructure of human and technical resources. These are frequently lacking in regions remote from the affluent neighbourhoods of major cities, whether in developed or developing economies. Moreover, potential users in these developing Knowledge Societies may have different needs or a different balance of needs from the established user base. Such neighbourhoods of major cities already provide an ICT ecology and their users' needs are heavily pre-determined by the prevailing Internet culture. In developing Knowledge Societies, however, the introduction of ICT - like any major infrastructure investment - is likely to be a communal decision, prioritised against other needs, and conditioned by local values. So the introduction of ICT into such a community needs to consider 1) what needs do we wish to meet, 2) what ICT infrastructure can meet those needs, and 3) how can we bootstrap the ICT ecology that will enable the deployment to become rapidly self-sustaining. The technology selection and deployment process thus requires a much broader assessment and the choices may - paradoxically - be wider than for an established Knowledge Society. In my contribution, I will propose a framework for preparing for the creation of a new Knowledge Society that is based in part on current experiments in developing economies and in part on a view of the evolution of the underlying technologies.

Key words: sustainable technology, technology diffusion 


\section{INTRODUCTION}

The scope of this discussion is the deployment in developing knowledge societies of information and communication technologies (ICT) for the direct use of the society. I assume that the fundamental challenges faced by such societies are: limited personal or social funding, limited technical infrastructures (electricity, communication networks), and limited skills. But other issues need consideration: what is the priority of ICT compared to other local needs (health, education, transportation), what needs and wants of the society as a whole should be addressed by ICT, and what will be the impact on the society of deploying ICT (new job opportunities, new cultural threats)?

This paper considers the unique characteristics of ICT and from these develops possible roadmaps to deployment based on the following principles:

1. What needs and wants do we wish to address by this deployment?

2. What forms of ICT can addresses the various classes of needs and wants?

3. How do we create a sustainable ICT infrastructure that addresses those needs and wants?

4. How do we evolve such an ICT infrastructure as the needs and wants and abilities of the society evolve?

\section{THE DIFFUSION OF TECHNOLOGIES}

As William Gibson famously remarked, "The future is here. It is just not widely distributed yet." It is a characteristic of all technologies that they are invented, piloted, and perfected locally among small groups of users before beginning the long haul to universal use. Geoffrey Moore has written about this transition in "Crossing the Gap" (Moore 2002). Early adopters of a new technology face considerable challenges: poor performance, poor reliability, poor support, and (relatively) high cost. They are motivated to use the technology because it provides some high value that is not otherwise available.

Consider the initial deployment of cellular telephones in the United States during the mid- to late-1980s. Initially the coverage provided was small and patchy, and there was no provision for roaming. The services were expensive relative to fixed network telephony. They also represented an enormous, speculative investment on the part of the cellular carriers. Cellular telephony found early adopters among people who were mobile within small areas, typically a single town, and for whom the advantage of mobile telephony offset the high monthly bills - lawyers, doctors, and 
property agents. Christensen has written widely on how emerging technologies find their initial markets (Christensen 1997).

An early adopter community is an essential element for the successful deployment of a new technology. Without this community there is no way to "cross the chasm" and attract the much larger mainstream community. In the absence of an early adopter community, it is tempting to turn to government to carry the technology across this secondary gap. However, governments have historically proven to be poor sponsors for emerging technologies.

For the technology to "cross the chasm", it must appeal to users with less strong motivations. Only by expanding beyond the early adopters to the much larger mainstream communities can it achieve the returns to scale that enable the developers to recover their initial investments. Reaching larger user groups in turn means that the price of the product or service can be reduced. Early cellular telephony users frequently had bills of $\$ 1,000$ per month for service within their own town; today such service might cost as little as \$25 per month. Broad adoption also requires new levels of performance, reliability, ease of use, and support. Some of these characteristics - performance, reliability - become imbedded in the device or the service as the developers capture their learning into the technology; their costs are easily recovered as the scale of use expands. Others - ease of use, support - have costs that increase in parallel with the scale of use. To succeed, the new technology must also find a financial model that enables its deployment to be sustainable.

The secondary diffusion of a technology into regions away from its origins poses a new set of challenges. While by the time of secondary diffusion, many of the core performance and reliability issues will have been resolved, it may be harder to find an early adopter community that will justify the initial deployment costs. The regions of secondary diffusion will often have different needs and wants from those of the technology's birthplace and there may be no early adopter community that can derive high value from the initial deployment.

For a technology to diffuse into a developing society there must be an infrastructure that contains the following features:

1. A minimum level of service or benefit that meets a key set of needs and wants of some members of the society.

2. A set of technologies that is affordable by those members of the society.

3. A collection of centralised and end-user skills that is sufficient to deploy, operate, and use the technology to meet the key wants and needs.

4. A set of technical, commercial, and educational mechanisms that enables the new technology to become indigenous rather than exotic and to expand its accessibility to the broader community. 


\section{CHARACTERISTICS OF ICT}

ICT shares many features with other 19-20C technologies, but it takes some of these to extremes not found elsewhere. In part these account for some of its amazing success in the last 30 years, but they also represent challenges for its successful deployment in emerging knowledge societies.

\section{Positive returns to scale}

A key feature of the economics of ICT is the extreme positive returns to scale, which is due in large part to the success of Very Large-Scale Integration. Computers of the 1960s were largely hand-built using tens of thousands of discrete transistors and they cost of the order of a million US dollars. Today's microprocessors are manufactured by enormously expensive semiconductor factories with a globally-integrated supply chain and produce chips containing hundreds of millions of transistors that cost of the order of hundreds of US dollars. This massive reduction in cost per function has been achieved because of the dramatic increase in volumes from a few thousand computers per year in the 1960s, to hundreds of millions of computers and other digital devices today.

A consequence of this positive-returns-to-scale model and of the massive investment required to develop a new device or a new manufacturing capability is that it appears unlikely that non-mainstream semiconductor or storage technologies will play a major role in deploying ICT into developing knowledge societies. While we can imagine meeting the needs and wants of such societies with simpler devices (chips), such approaches face insurmountable challenges in "crossing the chasm"; that is, in achieving sufficient volumes to reduce unit costs below the costs of mainstream devices.

\section{Generations of technology}

A second key feature of ICT is the generations of technology. These generations have been dominated to some degree over the last 20 years by the symbiosis of Intel's microprocessor generations and Microsoft's operating system generations. Through the leadership of these and other ICT vendors, the industry has had a well-defined rhythm.

So an alternative approach to deploying ICT in developing knowledge societies might be to use older generations of technology. Towards the end of a product lifecycle, the investment costs have been recovered and it 
becomes a "milk cow" that can be sold just above its marginal cost of production to drive volume until the industry is ready for the next generation. So it is conceivable to produce low-cost personal computers using older generation microprocessors, smaller amounts of physical memory, storage, and lower resolution displays.

However, devices are only part of the story and there is a limitation of this approach due to the vertical integration of the ICT industry as a whole. The generations of technology sweep through the industry from top to bottom: from the machines that produce the chips, to the machines that assemble devices onto boards and into systems, to the operating systems and device drivers that provide useful platforms, and the applications that provide end-user services. While there are capabilities within the industry to provide legacy support, they extend only so far back. The further we fall behind industry generations, the greater the likelihood that we have to provide this legacy support ourselves.

\section{Centralisation of skills}

A third key characteristic is the ability of ICT to embed knowledge within its products. For example, early personal computing required detailed knowledge of how to set up the signals that enabled a modem to interact with the Central Processing Unit (CPU). This involved hours of exploring combinations of "DIP switch" settings. Today, that knowledge is captured in industry standards and the operating systems that automate the integration of devices with the CPU. In the context of introducing technology into developing knowledge societies, this is good; we do not have to develop support skills for these tasks.

This is true of all technologies, for example cars, but ICT is an extreme case. In the $20 \mathrm{C}$ we saw that wherever a society was able to amass competency in metallurgy, mechanical engineering, chemical engineering, and manufacturing engineering, an automobile manufacturing industry could arise from the ground up. This was true also for ICT manufacturing up to circa 1970 , when the degree of integration within the industry was relatively small. But since then ICT has spread by the export of knowledge from a small number of developed knowledge societies into regions with lower manufacturing costs. The transition of that exogenous knowledge into indigenous knowledge does take place, but slowly relative to the development of the knowledge. The Internet Protocols and the work of the open standards bodies in general are great exceptions to this principle.

Since ICT is a delivery mechanism for skills, it is also possible for needed skills to be provided outside the area of deployment. For example 
via remote system management can to some extent reduce the need for local skills. On the other hand, such knowledge is and will remain exogenous to the society, and as time goes by, local skills that have been developed will (rapidly) become obsolete. So in planning a sustainable deployment, we need to consider carefully what the profile of needed skills will be over the coming years. This planning also needs to take into account the future uses of ICT will be used within the society.

\section{Product or service?}

Today's social use of ICT reflects the values, skills, and finances of the middle classes of westernised societies. It is predicated on the ability of a family to invest of the order of US\$1,000 in a personal computer that is replaced every 3-5 years and of the order of US\$20 per month in communication services. The ability to master the evolving end-user role has been viewed as a key social skill, just as the ability to perform automobile servicing was once viewed as a test of manhood.

The perceived benefits of this investment of money and learning are communication (e-mail), access to information (entertainment, education, financial management), e-commerce (shopping, micro-scale business), and community (chatrooms, clubs, on-line gaming). These have evolved rapidly since 1992, when e-mail became recognised as the "killer application" that induced of the order of a few million end-users to make these investments. Each succeeding set of benefits has built on the infrastructure created by the previous set and has been driven by - or been enabled by - succeeding generations of technology.

Western middle-class society experienced ICT as a set of products with supporting services for two main reasons: 1) a significant part of the required technology needs to be installed at the point of use and 2) the rapid evolution of the applications and benefits - combined with the rapid evolution of the technology - meant that no viable business models evolved for a servicebased approach to ICT. Contrast this with the telephone which emerged and has continued to be experienced primarily as a service with few private individuals owing and operating a home Private Branch Exchange (PBX).

We see in the above a number of economic and technical features that facilitate the introduction of ICT into developing knowledge societies and others that are inhibitors. In the next section we consider how these key features of ICT suggest different approaches to this deployment of ICT from those that have driven its deployment in Western middle-class societies. 


\section{A FRAMEWORK FOR THE ADOPTION OF ICT IN DEVELOPING KNOWLEDGE SOCIETIES}

These key features of ICT can give a set of policies for considering the set of questions given in the Introduction:

1. What needs and wants do we wish to address by this deployment?

2. What forms of ICT can address the various classes of needs and wants?

3. How do we create a sustainable ICT infrastructure that addresses those needs and wants?

4. How do we evolve such an ICT infrastructure as the needs and wants and abilities of the society evolve?

\section{Needs and wants}

From Moore (Moore 2002) we saw the need to find the initial community of early adopters who will provide the seed from which a broader deployment will grow. These early adopters will be people for whom (simple) ICT can provide high value relative to the costs. Some such community must be found in which ICT provides a better solution to some important want or need than existing alternatives. Table 1 shows possible assessments of these wants and needs and their possible values for various members of a developing knowledge society.

Table 1. is not prescriptive; it merely suggests possible benefits for some of the roles in societies. The people in these roles may or may not see that ICT can effectively meet their wants and needs. Even in highly developed Western countries, farmers are not early adopters of ICT, preferring instead to use the telephone. However in considering a deployment, such an analysis should be conducted. If no group or groups of people can be found to form an early adopter community of a sufficient size to provide the financing - through the purchase of goods and services - for the needed infrastructure (see below) then it is unlikely that a sustainable deployment can be achieved.

\section{What form of ICT?}

The above analysis will give a good idea of what initial set of ICT services is required. However the categories of service (e-mail, access to information, and so forth) can be provided with differing levels of service compared to those expected in developed knowledge societies. For example, 
in developed knowledge societies e-mail has lost its original connotation of an asynchronous service and is often used as a form of chat service with almost real-time interchanges. Some years ago the MIT Media Lab demonstrated that e-mail could in fact be provided without any networking infrastructure. The researchers created a mobile system transported on a motorcycle that could perform daily pickup and delivery of e-mail from servers located in isolated villages. Similar creativity can be applied to access to information, e-commerce, and communities.

Second, the technical level of the systems employed can be assessed. While we have noted that there are limitations to the use of older generations of technology, what compromises can be made in function and performance that will enable older technologies to be employed?

Table 1. Social roles and potential benefits of ICT services

\begin{tabular}{|c|c|c|c|c|}
\hline Role & Email & $\begin{array}{l}\text { Access to } \\
\text { information }\end{array}$ & e-commerce & community \\
\hline Student & $\begin{array}{l}\text { Simple e- } \\
\text { learning }\end{array}$ & $\begin{array}{l}\text { Opportunity for } \\
\text { higher levels of } \\
\text { education }\end{array}$ & $\begin{array}{l}\text { Selling/buying } \\
\text { coaching } \\
\text { services }\end{array}$ & $\begin{array}{l}\text { Collaboration } \\
\text { with other } \\
\text { students. } \\
\text { Experience of } \\
\text { other cultures }\end{array}$ \\
\hline Artisan & $\begin{array}{l}\text { Simple e- } \\
\text { commerce }\end{array}$ & $\begin{array}{l}\text { Awareness of } \\
\text { demand for } \\
\text { styles, prices }\end{array}$ & $\begin{array}{l}\text { Micro-business, } \\
\text { access to } \\
\text { markets }\end{array}$ & $\begin{array}{l}\text { New markets, } \\
\text { sharing of } \\
\text { techniques }\end{array}$ \\
\hline Farmer & $\begin{array}{l}\text { Simple e- } \\
\text { commerce }\end{array}$ & $\begin{array}{l}\text { Awareness of } \\
\text { demand for } \\
\text { products, prices }\end{array}$ & $\begin{array}{l}\text { Micro-business, } \\
\text { choice of } \\
\text { markets }\end{array}$ & $\begin{array}{l}\text { Cooperatives, } \\
\text { negotiating } \\
\text { organisations }\end{array}$ \\
\hline $\begin{array}{l}\text { Nurse or general } \\
\text { Medical Doctor }\end{array}$ & $\begin{array}{l}\text { Request to } \\
\text { hospitals, } \\
\text { pharmacies }\end{array}$ & $\begin{array}{l}\text { Treatments, } \\
\text { medical alerts, } \\
\text { epidemics, } \\
\text { continuing } \\
\text { education }\end{array}$ & $\begin{array}{l}\text { Buying medical } \\
\text { supplies, choice } \\
\text { of suppliers }\end{array}$ & $\begin{array}{l}\text { Communities of } \\
\text { practice }\end{array}$ \\
\hline Merchant & $\begin{array}{l}\text { Simple e- } \\
\text { commerce }\end{array}$ & $\begin{array}{l}\text { Awareness of } \\
\text { demand for } \\
\text { styles, prices }\end{array}$ & $\begin{array}{l}\text { Buying stock, } \\
\text { choice of } \\
\text { suppliers }\end{array}$ & $\begin{array}{l}\text { Buying } \\
\text { cooperatives }\end{array}$ \\
\hline All & $\begin{array}{l}\text { Staying in touch } \\
\text { with extended } \\
\text { family and } \\
\text { friends }\end{array}$ & $\begin{array}{l}\text { Awareness of } \\
\text { the region, } \\
\text { country, world. }\end{array}$ & Increased choice & $\begin{array}{l}\text { Experience of } \\
\text { other cultures }\end{array}$ \\
\hline $\begin{array}{l}\text { Alternative } \\
\text { solutions }\end{array}$ & $\begin{array}{l}\text { Mail, personal } \\
\text { travel }\end{array}$ & $\begin{array}{l}\text { Libraries, } \\
\text { newspapers, } \\
\text { circulating } \\
\text { letters }\end{array}$ & $\begin{array}{l}\text { Local markets, } \\
\text { wholesalers }\end{array}$ & $\begin{array}{l}\text { Local trade } \\
\text { associations, } \\
\text { newsletter, travel } \\
\text { to meetings }\end{array}$ \\
\hline
\end{tabular}


Third, should ICT be made available as a product or a service? The Western middle-class experience is perhaps a reflection of the decline of social capital in Western societies during the last 60 years (Putnam 2000). Other societies may prefer a more communal model for the initial ICT deployment, even if it is initially sponsored by the early adopters.

\section{How to achieve sustainability?}

Inevitably the introduction of ICT into developing knowledge societies begins with exogenous technology and skills. How should the society go about achieving sustainability? There is a tendency to want to create local industries for PC manufacture, but in reality this offers poor opportunities for sustainability.

Table 2. Value network for ICT products and services

\begin{tabular}{|c|c|c|}
\hline Technology & Accessibility & $\begin{array}{l}\text { Opportunity for local value } \\
\text { addition }\end{array}$ \\
\hline $\begin{array}{l}\text { Personal computer } \\
\text { management }\end{array}$ & High & $\begin{array}{l}\text { High, probably difficult to } \\
\text { provide remotely }\end{array}$ \\
\hline $\begin{array}{l}\text { Server operation } \\
\text { (architecture, service } \\
\text { definition, tariffs) }\end{array}$ & High & High \\
\hline Server management & High & $\begin{array}{l}\text { High, though could be } \\
\text { provided remotely }\end{array}$ \\
\hline $\begin{array}{l}\text { Network operation } \\
\text { (architecture, policies, tariffs) }\end{array}$ & $\begin{array}{l}\text { High, but needs high skill } \\
\text { levels }\end{array}$ & High \\
\hline Network management & $\begin{array}{l}\text { Moderate, but needs high } \\
\text { skill levels }\end{array}$ & High \\
\hline Software installation & $\begin{array}{l}\text { High, mainly skill-based, } \\
\text { little capital required }\end{array}$ & High \\
\hline Software development & $\begin{array}{l}\text { Moderate through Open } \\
\text { Source Software } \\
\text { communities, but needs very } \\
\text { high skill levels }\end{array}$ & $\begin{array}{l}\text { Low, will not add significant } \\
\text { value in the short term }\end{array}$ \\
\hline $\begin{array}{l}\text { Hardware repair (computer } \\
\text { and network equipment) }\end{array}$ & $\begin{array}{l}\text { Moderate, mainly skill-based, } \\
\text { but may require some } \\
\text { electronic test gear, also spare } \\
\text { parts }\end{array}$ & High \\
\hline Hardware installation & $\begin{array}{l}\text { High, mainly skill-based, } \\
\text { little capital required }\end{array}$ & High \\
\hline Assembled systems & $\begin{array}{l}\text { Very low (very high capital } \\
\text { investment) }\end{array}$ & Minimal \\
\hline Chip and storage & $\begin{array}{l}\text { Extremely low (massive } \\
\text { capital investment) }\end{array}$ & Zero \\
\hline
\end{tabular}


Table 2. shows a partial hierarchy of the value network for ICT with a rough assessment of the ease with which each layer can be performed within a developing knowledge society and of the potential for contributing value to that society.

Because of the key features of ICT discussed above, the potential for contributing near the base of the stack is limited and the value that could be achieved is also limited. Moving upwards, better opportunities exist in acquiring the system and network architecture and operational skills needed to deploy ICT to meet the wants and needs of the community. These skills do require a quick mind, but do not require higher education. They are among the most valuable skills in the ICT industry and so there is a risk of leakage of the people with these away from the community (see however the discussion below on How to Evolve for the Future).

The ICT industry has a well established model of levels of support for products and services. Level 1 support can address the most common problems encountered by users, say, the top 90\%. Level 2 support can address more serious technical questions and perform diagnosis and some repair; this covers a further $8-9 \%$. Finally Level 3 support has deep knowledge of the products and services and can diagnose any problem. The deployment can thus leverage this hierarchy to provide Level 1 support on site with the others accessible more rarely via telephone or e-mail.

So the sustainable deployment model is based on:

1. Acquiring externally the minimal technical systems needed to support the wants and needs of the early adopters;

2. Temporarily importing the skills to set up and begin operation of these systems;

3. Making these available either as products or as services to an early adopter community;

4. Developing locally the Level 1 support skills that must be delivered locally;

5. Relying on remote Level 2 and Level 3 support;

6. Eventually developing some Level 2 and 3 capabilities.

\section{How to Evolve for the Future?}

If a sustainable deployment of systems and skills, founded on meeting the affordable wants and needs of a community of early adopters, can be established, then there is good potential for "crossing the chasm" into broader adoption. This results in economies of scale reducing the cost of service and enabling additional services to be provided. This is predicated 
on a general economic expansion enabled or supported by the early adopter usage.

There are models of economic development based on the introduction of motor cycles leading to a growth in per capita income and in turn to a transition to cars; each stage generating new skills and commercial opportunities. No such bootstrap model based on ICT has been demonstrated. There have been claims of increased commercial productivity in Western societies, but these have been challenged recently (Henwood 2003).

The early history of mobile telephone operators and Internet Service Providers (ISP) is perhaps instructive. The strategy of both these groups was initially to find early adopters to enable them to get into the business and then to reduce prices and acquire as many mainstream users as possible with the aim of being bought out by a large telecommunication company or large ISP. This seems a likely course of events for these deployments of ICT into developing knowledge communities. Just as large, mainstream airlines are effectively unable to establish low-cost subsidiaries, so large telecommunication companies or ISPs are unable to engage in this form of ICT deployment. However, once a deployment is successful, it will form an attractive takeover target for such an operator and this could bring a significant capital infusion into the community.

My own belief is that the greatest value of ICT into developing knowledge communities comes not from the services themselves, but from the consequential emergence of new patterns of thinking within the community and the development of new skills that enable the community to take part in the broader economic activities of the region or worldwide.

\section{CONCLUSIONS}

The deployment of ICT in developing knowledge societies poses a set of choices that reflect the unique features of these technologies, the economics of bootstrapping new technologies, and the specific needs of the community. Alternatives exist to the Western middle-class model of ICT, notably the delivery of ICT as a set of services rather than products. The opportunities for developing sustainability in the ICT deployment are most likely to be in the operation and management of the systems and services rather than in the development of hardware or software systems and this can bring highly valuable new skills to the community. The ultimate success of such a deployment is probably identified by the acquisition of the community's systems and services into a larger organisation, but will leave the community enriched with new skills and opportunities. 


\section{BIOGRAPHY}

Colin Harrison joined IBM in San Jose, California in 1979 and has held many technical leadership positions in IBM's product businesses, in IBM's Research Division, and currently in IBM's IT services business. In 2001 he established IBM's Institute for Advanced Learning. Following his university studies, he spent several years at CERN developing the SPS accelerator. He then returned to EMI Central Research Laboratories in London, and lead the development of the world's first commercial MRI system. With IBM he has enjoyed a career leading from micromagnetics to medical imaging, parallel computing, mobile networking, intelligent agents, telecommunications services, and knowledge management.

Colin studied Electrical Engineering at the Imperial College of Science and Technology and earned a PhD in Materials Science. He also studied Physics at the University of Munich. He is a Fellow of the Institution of Electrical Engineers (UK) and a Senior Member of the Institution of Electronic and Electrical Engineers (USA). $\mathrm{He}$ is a Chartered Engineer (C.Eng.) and a European Engineer (Eu Ing). He was a founder member of the Society of Magnetic Resonance in Medicine (USA). He is also an expert advisor to the Swiss Academy of Technical Sciences. He has been a visiting scientist at MIT, Harvard Medical School, and Lawrence Berkeley Laboratory.

Colin Harrison has been awarded 26 patents. He has published some 40 scientific and technical papers and talks and a successful book on Intelligent Agents. He is an invited speaker at European universities on the impact of information technology on the nature of work, business organisation, and industries.

\section{REFERENCES}

Moore, G. A (2002) Crossing the Chasm, HarperBusiness, ISBN 0-0605-1712-3.

Christensen, C. M. (1997) The Innovator's Dilemma, Harvard Business School Press, ISBN $0-8758-4585-1$.

Putnam, R. D. (2000) Bowling Alone: The Collapse and Revival of American Community, Simon \& Shuster, ISBN 0-684-83283-6.

Henwood, D. (2003) After the New Economy, New Press, ISBN 1-5658-4770-9. 